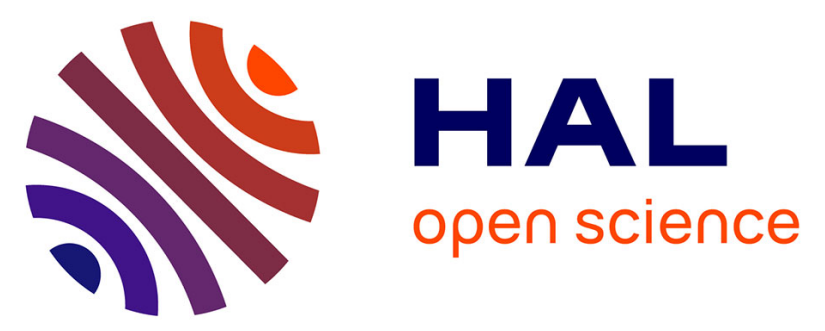

\title{
Prenatal and 5-year p,p'-DDE exposures are associated with altered sensory processing in school-aged children in Nunavik: A visual evoked potential study.
}

Chloé Cartier, Gina Muckle, Sandra W Jacobson, Joseph L Jacobson, Eric Dewailly, Pierre Ayotte, Cécile Chevrier, Dave Saint-Amour

\section{To cite this version:}

Chloé Cartier, Gina Muckle, Sandra W Jacobson, Joseph L Jacobson, Eric Dewailly, et al.. Prenatal and 5-year p,p'-DDE exposures are associated with altered sensory processing in school-aged children in Nunavik: A visual evoked potential study.. NeuroToxicology, 2014, 44C, pp.8-16. 10.1016/j.neuro.2014.04.009 . hal-01061309

HAL Id: hal-01061309

https://hal-univ-rennes1.archives-ouvertes.fr/hal-01061309

Submitted on 5 Sep 2014

HAL is a multi-disciplinary open access archive for the deposit and dissemination of scientific research documents, whether they are published or not. The documents may come from teaching and research institutions in France or abroad, or from public or private research centers.
L'archive ouverte pluridisciplinaire HAL, est destinée au dépôt et à la diffusion de documents scientifiques de niveau recherche, publiés ou non, émanant des établissements d'enseignement et de recherche français ou étrangers, des laboratoires publics ou privés. 


\title{
Prenatal and 5-year $p, p$ '-DDE exposures are associated with altered sensory processing in school-aged children in Nunavik: A visual evoked potential study
}

\author{
Chloé Cartier ${ }^{\mathrm{a}, \mathrm{b}}$, Gina Muckle ${ }^{\mathrm{c}, \mathrm{d}}$, Sandra W. Jacobson ${ }^{\mathrm{e}}$, Joseph L. Jacobson ${ }^{\mathrm{e}}$, Éric Dewailly ${ }^{\mathrm{d}, \mathrm{f}}$, \\ Pierre Ayotte $^{\mathrm{d}, \mathrm{f}}$, Cécile Chevrier ${ }^{\mathrm{b}}$ and Dave Saint-Amour ${ }^{\mathrm{a}, \mathrm{g}}$
}

\begin{abstract}
${ }^{a}$ Département de psychologie, Université du Québec à Montréal, 320 Sainte-Catherine Est Pavillon J.A. De Sève, local DS5775, Montréal, Québec, Canada. H2X 1L7

${ }^{\mathrm{b}}$ INSERM U1085, Université Rennes I, 263 Avenue du Général Leclerc, 35042 Rennes, France ${ }^{c}$ École de psychologie, Université Laval, 2325, rue des Bibliothèques, Québec (Québec), Canada, G1V 0A6.

${ }^{\mathrm{d} A x e}$ santé des populations et pratiques optimales en santé, Centre de recherche du CHU de Québec, 2875 boul. Laurier, Québec (Québec), Canada, G1V 2M2.

${ }^{e}$ Department of Psychiatry and Behavioral Neurosciences, Wayne State University, 3901 Chrysler Drive, Suite 2-C, Detroit, Michigan, MI 48201, United States.

${ }^{\mathrm{f}}$ Département de médecine sociale et préventive, Faculté de Médecine, 1050, avenue de la Médecine, Pavillon Ferdinand-Vandry, Université Laval, Québec (Québec), Canada, G1V 0A6.

${ }^{g}$ Centre de recherche et département d'ophtalmologie, CHU Sainte-Justine, 3175 Chemin de la Côte Sainte-Catherine, Montréal, (Québec), Canada, H3T 1C5.
\end{abstract}

Corresponding author: Dave Saint-Amour, Université du Québec à Montréal, 320 SainteCatherine Est, Pavillon J.A. De Sève, Montréal, Québec, Canada. H2X 1L7 Phone (514) 987-3000 \# 7698, fax: (514) 987-7953; email: saint-amour.dave@uqam.ca 


\begin{abstract}
Due to their geographic location and traditional diet, rich in seafood and marine mammals, the Inuit living in Arctic Quebec are exposed to high amounts of pollutants, including organochlorine pesticides (OCPs). While the adverse developmental effects of these pesticides on child cognitive functions are well known, the effects of developmental exposure to OP on sensory processes have not been investigated. The aim of this longitudinal study was to assess the effects of prenatal and childhood exposure to 1,1,1trichloro-2,2-bis( $p$-chlorophenyl)ethane ( $p, p^{\prime}$-DDT) and its major metabolite 1,1,-dichloro2,2-bis( $p$-chlorophenyl)ethylene ( $p, p^{\prime}$-DDE), on visual processing in Inuit children in Nunavik (Arctic Québec). p,p'-DDT and p,p'-DDE concentrations were determined from umbilical cord and 5- and 11-year plasma samples. Visual evoked potentials (VEPs) were successfully recorded in 150 children at four contrast levels $(95 \%, 30 \%, 12 \%$, and 4\%). Hierarchical multiple regressions were conducted to determine the association between $p, p$ 'DDT, or $p, p$ '-DDE, exposure and VEPs while controlling for the effects of various confounders, including fish nutrients and other contaminants. $p, p$ '-DDE measured in umbilical cord plasma was significantly related to the amplitude of the N150 response at the lowest contrast (4\%). In addition, 5-year $p, p^{\prime}$-DDE plasma concentration was significantly associated with decreased N75 amplitude. These findings indicate that $p, p$ '-DDE exposure, both pre- and postnatally, during early childhood is associated with visual processing impairment later in life.
\end{abstract}

Keywords: Neurotoxicity, $p, p^{\prime}$-DDT, $p, p^{\prime}$-DDE, Visual Evoked Potentials, Sensory processing 


\section{Introduction}

Organochlorine pesticides (OCPs) are widespread contaminants. These industrially synthesized chlorine compounds were used extensively in agriculture and residential settings from the 1930s to the mid-1980s. OCPs are included in the group of environmental endocrine disruptors known as persistent organic pollutants (POPs). Most of them have been banned under the international Stockholm Convention due to their persistence in the environment, their ability to be stored in fatty tissues, and their high toxicity for wildlife and humans, although some OCP continue to be used in industrialized and developing countries. Studies have demonstrated adverse associations of these chemicals with human health, including cancer (Cohn et al., 2007, McGlynn et al., 2008, Multigner et al., 2010, Romieu et al., 2000), as well as metabolic (Montgomery et al., 2008, Patel et al., 2010), immune (Dewailly et al., 2000, Hermanowicz et al., 1982), and reproductive (De Jager et al., 2006) dysfunctions.

During gestation, OCPs can reach the fetus by crossing the placenta (Sala et al., 2001, Shen et al., 2008). Postnatal exposure to these toxicants occurs via breastfeeding, and later in life through food, house dust (Abb et al., 2010), and water consumption (Diaz et al., 2009, Kaushik et al., 2012). The adverse effects of prenatal exposure to these chemicals on neurodevelopment, especially child cognition and behaviors, are well documented (Korrick and Sagiv, 2008), and can be explained by the fact that the developing brain, from early embryologic life to adolescence, is extremely sensitive to toxic disturbances. Perturbations of complex maturational processes by OCP or other organochlorine compounds, such as polychlorinated biphenyls (PCBs), can lead to brain damage or more subtle functional alterations, which are detectable early in life and in later development (Grandjean and Landrigan, 2006, Jacobson and Jacobson, 1996).

In recent decades, prenatal exposure to various OCP has been related to impaired attention, working memory deficits (Puertas et al., 2010), hyporeflexia (Rogan et al., 1986), poorer social performance, and attention deficit hyperactivity disorder (ADHD) symptoms (Ribas-Fito et al., 
2007). Numerous studies have focused on the effects of $p, p^{\prime}$-DDT and its major metabolite, $p, p$ 'DDE, on cognitive neurodevelopment. A prospective birth cohort study assessing child development in Spain showed an association between cord $p, p$ '-DDE concentration and mental and psychomotor development delays at age 13 months (Ribas-Fito et al., 2003). A follow-up study of these children 3 years later revealed an adverse impact of cord serum $p, p$ '-DDT concentration on verbal, memory, and perceptual scores on the McCarthy Scales of Children's Abilities (Ribas-Fito et al., 2006). Other studies have found evidence of the adverse effects of prenatal exposure to $p, p$ 'DDE and p,p'-DDT on psychomotor or mental development in childhood (Eskenazi et al., 2006, Torres-Sanchez et al., 2007). More recently, in utero DDE exposure was also related to ADHD-like behaviors in a cohort of 607 children aged from 7 to 11 years (Sagiv et al., 2010). The impact of $p, p^{\prime}$-DDT or $p, p^{\prime}$-DDE exposure on sensory development is unknown.

OCP are found in polar regions, where they are carried from industrialized and developing countries by marine and atmospheric currents and bioaccumulated in the food chain due to their lipophilic properties (Barrie et al., 1992). Given their geographic location and traditional diet of seafood and marine mammals, Inuit people living in Canada's Arctic Quebec, a region called Nunavik, are exposed to high levels of several environmental contaminants, including organochlorine compounds (Dewailly et al., 1993, Muckle et al., 2001). By way of comparison, prenatal exposure to organochlorine products is about two to three times higher in Nunavik than in other North American regions (Muckle et al., 2001). Prenatal exposure to organochlorine compounds, in particular PCBs, has been related to alterations in emotional (Plusquellec et al., 2010), cognitive, behavioral (Boucher et al., 2012) and visual functions (Saint-Amour et al., 2006). Using visual evoked potential (VEP) recordings, Saint-Amour et al. (2006) demonstrated impairments in visual brain function in preschool Inuit children in Nunavik relating to postnatal PCB exposure. However, using the same method, a follow-up VEP study in children aged 11 years found no significant effect from PCB exposure on visual processing (Ethier et al., 2012). 
Scalp-recorded VEP is a sensitive and non-invasive electrophysiological method commonly used in pediatric populations to assess the maturation and functional integrity of brain processes (Otto, 1987). Alterations in VEP amplitude or latency are thought to reflect damage along visual pathways, including subclinical alterations in visual processing due to environmental contaminants (Ethier et al., 2012, Jacques et al., 2011, Murata et al., 1999, Saint-Amour et al., 2006). Compared to behavioral performance, using electrophysiological recording to assess sensory processes provides a more direct measure of brain function. Because vision depends on the maturation and integrity of the retina, optic tract, and visual cortex, measuring electrical visual activity may provide a more accurate picture of OCP exposure neurotoxicity, with the additional advantage of revealing subclinical effects.

A recent VEP study conducted in Nunavik to assess child visual development in relation to heavy metal and PCB exposure (Ethier et al., 2012) found that cord blood concentrations of lead and mercury were associated with decreased VEP amplitude in 11-year-old children. No significant association with PCB exposure was found. The aim of the present longitudinal study was to assess the relation of $p, p^{\prime}$-DDT and its $p, p$ '-DDE metabolite exposures with visual brain integrity by examining prenatal and childhood exposures. After PCBs, $p, p^{\prime}$-DDT, and particularly $p, p^{\prime}$-DDE, is the most prevalent organochlorine compound in Nunavik. Because the Inuit are exposed to high amounts of omega-3 polyunsaturated fatty acids (n-3 PUFAs), due to their traditional seafood diet, and because n-3 PUFAs are widely recognized for their beneficial role in vision development and function (Molloy et al., 2012, Morse, 2012), exposure to n-3-PUFAs was adjusted statistically in the data analysis, along with other potential confounding variables.

\section{Methods}

\subsection{Participants}


A total of 294 school-age Inuit children from Nunavik participated in an 11 follow-up study. From these children, 172 participated in the present VEP study (range $=10$ to 13 years, mean \pm standard deviation $=10.9 \pm 0.6$ ) (see Ethier et al., 2012 for more details). These children were originally recruited under the 1993-1998 Cord Blood Monitoring Program, which aimed to document the exposure of Inuit newborns to environmental contaminants by using umbilical cord samples (Muckle et al., 1998). Three groups of Inuit mothers and their children were invited to participate in the 11-year follow-up assessment, according to the following categories: 1) children who had participated in the Environmental Contaminants and Child Development Study as infants (Jacobson et al., 2008, Muckle et al., 2001), 2) children who had participated in the Nunavik Preschool Study at age 5 years (Saint-Amour et al., 2006), and 3) children for whom cord blood samples were available but had not been previously tested. Mothers living in the three largest Nunavik villages were contacted by telephone, informed about the study procedures, and invited to participate. Inclusion criteria were 8.0 to 15.0 years of age, birth weight $\geq 2.5 \mathrm{~kg}$, gestation duration $\geq 35$ weeks, no known neurologic or clinically significant developmental disorder, and no use of medication at the time of testing. A maternal interview was conducted at the time of testing to collect information about tobacco, drug, and alcohol use during pregnancy, and to document potential confounding variables, such as quality of parental intellectual function and sociodemographic and psychosocial factors. Written informed consent was obtained from one parent of each participant, and oral assent was obtained from each child. The research procedures were approved by the ethics committees of Wayne State University, Laval University, and SaintJustine Hospital.

\subsection{Visual Evoked Potentials}

As described in detail in Ethier et al. (2012), a standard pattern reversal VEP procedure was used. Vertical sinusoidal gratings with a spatial frequency of 2.5 cycles per degree were presented using Presentation ${ }^{\circledR}$ software (Neurobehavioral Systems, Inc. San Paolo, CA) at a reversal rate of $1.1 \mathrm{~Hz}$ 
at four visual contrasts from high to low visibility, i.e., at 95, 30, 12 and 4\%. Contrast was defined according to the Michelson's formula to keep the mean luminance constant: (maximal luminance minimal luminance $) /($ maximal luminance + minimal luminance $) \times 100$. Stimuli were presented to the children binocularly from a distance of $57 \mathrm{~cm}$ in a dimly lit room $\left(24^{\circ} \times 24^{\circ}\right.$ of visual field $)$. The experimenter was blind to participant information. Children were instructed to concentrate on a small red dot located at the center of the screen. The electro-oculograms (EOG) were recorded from the outer canthus of each eye (horizontal EOG) and above and below the right eye (vertical EOG). VEPs were scalp-recorded over the occipital central site $(\mathrm{Oz}$ derivation according to the International 10-20 system) with an $\mathrm{Ag}-\mathrm{AgCl}$ electrode using InstEP software (InstEP Inc., Montreal, Canada). The reference and ground electrodes were located at the frontal central site (Fz derivation according to the International 10-20 system) and on the forehead, respectively. Impedance was kept below $5 \mathrm{k} \Omega$. The electro-encephalogram (EEG) signal was amplified and band-pass filtered at $0.1-100 \mathrm{~Hz} .100$ trials were recorded at each contrast. Pattern reversal VEPs were time-locked to stimulus onset and averaged (sweep time, $500 \mathrm{~ms}$; pre-stimulus delay, $50 \mathrm{~ms}$; sampling rate, $1000 \mathrm{~Hz}$ ). Trials in which the response was higher than $75 \mu \mathrm{V}$ at any recording site (horizontal EOG, vertical EOG, or $\mathrm{Oz}$ ) were rejected before averaging to eliminate ocular and muscular artifacts. The following standard VEP components were examined: N75 (negative deflection at $\approx 75 \mathrm{~ms}$ after the stimulus onset), P100 (positive deflection at $\approx 100 \mathrm{~ms}$ after the stimulus onset), and N150 (negative deflection at $\approx 150 \mathrm{~ms}$ after the stimulus onset) (Odom et al., 2004). For each component, the latency, i.e., the time in ms from stimulus onset to the largest amplitude of a positive or negative deflection, was calculated as well as the amplitude (response intensity in $\mu \mathrm{V}$ ) was calculated from baseline to peak. All EEG analyses were performed with Analyzer 2 software (Brain Products, Inc., Munich, Germany).

\subsection{Biological measures}


Documentation of prenatal exposure to several persistent organic pollutants was available from the Cord Blood Monitoring Program. The analyses were performed at the Laboratoire de Toxicologie INSPQ, which is accredited by the Canadian Association for Environmental Analytical Laboratories. Detailed analytical and quality control procedures have been described previously (Boucher et al., 2010a, Boucher et al., 2010b, Boucher et al., 2009, Muckle et al., 2001, Rhainds et al., 1999). The 14 most prevalent PCB congeners (IUPAC nos. 28, 52, 99, 101, 105, 118, 128, 138, $153,156,170,180,183,187)$, and 11 organochlorine pesticides or their metabolites (aldrin, $\alpha$ chlordane, $\beta$-chlordane, $p, p$ '-DDT, $p, p$ '-DDE, $\mathrm{HCB}, \beta-\mathrm{HCH}$, mirex, cis-nonachlor, trans-nonachlor, oxychlordane) were measured in purified plasma extracts using high-resolution gas chromatography (Hewlett-Packard HP5890A), with two capillary columns (Hewlett-Packard Ultra I and Ultra II) and dual Ni-63 electron capture detectors. PCB congener 153 was used as an indicator of total PCB exposure because it is highly correlated with other PCB congeners (Muckle et al., 2001) and is considered an adequate marker of exposure to environmental PCB mixtures (Ayotte et al., 2003). Total Hg concentrations were determined in umbilical cord blood samples using cold vapor atomic absorption spectrometry (Pharmacia Model 120). Blood Pb levels were determined by graphite furnace atomic absorption with Zeeman background correction (Perkin Elmer model ZL 4100). Se concentrations were determined by inductively coupled plasma mass spectrometry (ICP-MS) on a Perkin Elmer SciexElan 6000 instrument. The limits of detection (LODs) were $0.2 \mu \mathrm{g} / \mathrm{dL}$ for blood $\mathrm{Hg}$ and $\mathrm{Pb}, 0.1 \mu \mathrm{mol} / \mathrm{L}$ for $\mathrm{Se}$, and $0.02 \mu \mathrm{g} / \mathrm{L}$ for all $\mathrm{PCB}$ congeners and 11 organochlorine pesticides or their metabolites (aldrin, $\alpha$-chlordane, $\beta$-chlordane, $p, p$ '-DDT, $p, p$ '-DDE, HCB, $\beta$ $\mathrm{HCH}$, mirex, cis-nonachlor, trans-nonachlor, oxychlordane) in plasma. Docosahexaenoic acid (DHA), an important omega-3 fatty acid, was measured in plasma phospholipids at the University of Guelph Lipid Analytical Laboratory (B.J. Holub), as described in Jacques et al. (2011).

Child exposure was measured through a venous blood sample $(20 \mathrm{~mL})$ at 5 and 11 years on the day of testing. Concentrations of PCB congeners, and 11 organochlorine pesticides or their 
metabolites (aldrin, $\alpha$-chlordane, $\beta$-chlordane, $p, p^{\prime}$-DDT, $p, p^{\prime}$-DDE, $\mathrm{HCB}, \beta$-HCH, mirex, cisnonachlor, trans-nonachlor, oxychlordane) were measured in plasma extracts by gas chromatography (HP 5890 Series II Plus), equipped with a 30-m DB-5 (J\&W Scientific) and HP 5890B mass spectrometer (Agilent). Compounds were automatically extracted from the aqueous matrix using solid phase extraction. LODs were less than $0.05 \mu \mathrm{g} / \mathrm{L}$ for all PCB congeners and OPs, except for PCB $52(\mathrm{LOD}=0.15 \mu \mathrm{g} / \mathrm{L})$. Total $\mathrm{Hg}, \mathrm{Pb}$ and Se concentrations were determined in whole blood samples by ICP-MS (Perkin Elmer SciexElan 6000 ICP-MS instrument for Pb and Se; PE DRC II instrument for $\mathrm{Hg}$ ). LODs were $0.002 \mu \mathrm{g} / \mathrm{dL}$ for $\mathrm{Pb}, 0.10 \mu \mathrm{g} / \mathrm{L}$ for $\mathrm{Hg}$ and $0.09 \mu \mathrm{mol} / \mathrm{L}$ for Se. DHA was measured in plasma phospholipids using the same procedure as described above for umbilical cord plasma samples. Whenever chemical analysis yielded a "not detected" result, a value equal to half the limit of detection of the analytical method was entered in the database. All organochlorine compounds were expressed on a lipid basis for both prenatal and child exposures. For either prenatal or child exposure, OCPs that were not detected in more than $40 \%$ of the samples, that is aldrin, $\alpha$-chlordane, $\beta$-chlordane, $\beta$-HCH and mirex, were not included in the statistical analyses. This $40 \%$ criterion is based on the practice of the Center for Disease Control and Prevention (CDC) (Sjodin et al., 2008, Wang et al., 2009).

\subsection{Confounding factors}

Based on our previous VEP study (Ethier et al., 2012), the following potential confounding variables were examined: child's gender, age, and hemoglobin concentration at testing time, breastfeeding duration, maternal level of education, maternal parity, socioeconomic status of the primary caregiver (Hollingshead, 1975), maternal binge drinking episodes during pregnancy (yes/no) (> 5 standard drinks of alcohol per occasion), maternal drug and tobacco uses during pregnancy (yes/no). Additional potential confounders included prenatal and current exposure to other environmental contaminants (mercury and lead) known to have a negative impact on visual 
processing or child development, as shown previously in this population (Ethier et al., 2012, Plusquellec et al., 2010, Saint-Amour et al., 2006). The major fish nutrients selenium and DHA were also examined, DHA being well known for its beneficial impact on visual system development (Cartier and Saint-Amour, in press, Jacques et al., 2011). Because oxychlordane, cis-nonachlore, trans-nonachlore and PCB153 were highly correlated with $p, p^{\prime}$-DDT and $p, p$ '-DDE (rs range: 0.540.94), they were not included in the regression models to avoid multicolinearity.

\subsection{Statistical analysis}

Because the amplitude of some VEP component is by definition negative (i.e., N75 and N150), the analyses were conducted on the absolute values to avoid any ambiguity and facilitate the interpretation of the regression results. Descriptive statistics of the children, contaminants, and VEPs were examined for potential outliers and skewed distributions. Non-normally distributed variables were log-transformed. Pearson's correlations were then computed to examine the pattern of correlations between the contaminants measured at birth and at the time of testing.

The following 3-step selection strategy was used to restrict the number of multiple regression models in order to minimize Type I error. First, similarly to the method used by Ethier et al. (2012), each VEP component for both latency and amplitude was tested using repeated-measure analysis of variance (ANOVA), in which the four levels of visual contrast $(95,30,12$ and 4\%) served as a within-subjects measure, and the contaminant of interest (DDT or DDE at both cord or 11-year measurements) as a covariate. If the main or interaction (visual contrast level $\times$ contaminant) effect was significant $(\mathrm{p}<0.05)$, the VEP outcome was then submitted to the next step, which consisted of running Pearson's correlation between the contaminant and the dependent variable at each contrast level. When the correlation was at $\mathrm{p}<0.20$, multiple linear regression was conducted. This selection method yielded a total of 9 multiple linear regression models.

Multiple linear regression analyses were conducted following the hierarchical procedure used by Jacobson et al. (2008): 1) among the above-described control variables, each variable 
related to the VEP outcome of interest at $\mathrm{p}<0.20$ was selected; 2) the OCP variable was entered in the first step of the regression analysis and each potential confounder was then entered, starting with the confounder showing the highest correlation with the outcome and proceeding to the confounder showing the next highest correlation, etc.; 3) a confounder was retained in the model if its inclusion changed the association (standardized regression coefficient) between the OCP variable and the VEP outcome by at least $10 \%$ at entry. The 0.20 alpha level and $10 \%$ change criteria were based on the work of Maldonado and Greenland (1993). Cook's distance was calculated for the final regression models to detect potential influential points, using a cut-off of $4 \times p / n$, where $p$ is the number of predictors and $n$ is the number of subjects in the model. A sensitivity analysis was then conducted by re-running the model, omitting participants with influential points. The model was considered to be unduly influenced if the beta for a contaminant of interest changed by more than $10 \%$ without the influential points. Based on these criteria no participants were excluded from the regression analysis. The standardized residuals from each model were examined to check for model fit. All of the standardized residuals fell between -3.5 and 3.5.

\section{Results}

Children with abnormal visual acuity ( $\geq 20 / 30$ on the Snellen E chart) were excluded from the analysis for the following reason. Abnormal acuity is mainly related to refraction errors in the focusing of light on the retina. In the other words, if vision is corrected with adequate glasses, visual acuity becomes instantly normal. Because refraction error has drastic effects on VEPs (latency is increased and amplitude is decreased), it is not possible to distinguish effects of refraction error from the effects of alteration of visual processing (at the retina or cortex level). Furthermore, there is no data in the literature showing that $p, p^{\prime}-\mathrm{DDT}$ or $p, p^{\prime}$-DDE exposure is related to visual acuity. Accordingly, we did not find any correlation between abnormal visual acuity and exposure, or a difference of contaminant concentration between participants with glasses and participants without glasses. Thus of the initial sample of 172 participants, 21 children were excluded from the analyses 
on this acuity criteria (and one was excluded due to lack of cooperation), ending in a final sample of 150 valid participants. Because the VEP results reported do not include participants with apparent visual acuity deficits, any significant association in the present study is therefore revealing OCP subclinical neurotoxicity.

Descriptive statistics of the participants are presented in Table 1. Most of the characteristics of the 150 VEP study participants did not differ significantly from the 144 remaining children who were part of the 11-year follow up study, except for the selenium prenatal exposure and for marijuana use during pregnancy (Table 1). Girls and boys were equally represented in the sample (50.7\% girls, $49.3 \%$ boys). Median breastfeeding duration was 3 months. Of the mothers, $81.1 \%$ reported smoking during pregnancy on a regular basis, and $49.2 \%$ reported consuming alcohol during pregnancy.

\subsection{Contaminants and nutrient exposures}

As presented in Table 2, intercorrelations between cord blood and 11-year blood concentrations ranged from moderate to high. Intercorrelations between $p, p^{\prime}$-DDT and $p, p$ '-DDE were mostly moderate (rs range: $0.42-0.71$; median $=0.48$ ). On the other hand, oxychlordane, cis-nonachlore, trans-nonachlore and PCB153 were moderately to highly correlated with $p, p$ '-DDT or $p, p$ '-DDE atbirth (rs range: 0.57-0.89; median $=0.78$ ) and at 11 years ( $\mathrm{rs}$ range: $0.54-0.94$; median $=0.82$ ). Organochlorine compound concentrations ( $p, p^{\prime}$-DDT, $p, p^{\prime}$-DDE, oxychlordane, cis-nonachlore, trans-nonachlore and PCB153) measured at birth were weakly to moderately correlated with 11year organochlorine compound concentrations ( $r$ range: $0.41-0.57$; median $=0.46$ ).

Mean concentrations and ranges of $p, p^{\prime}-\mathrm{DDT}, p, p^{\prime}-\mathrm{DDE}, \mathrm{PCB} 153, \mathrm{~Pb}$ and $\mathrm{Hg}$, as well as nutrients are reported in Table 3. p,p'-DDE was found in all umbilical cords and childhood plasma samples, whereas p,p'-DDT was detected in $79.9 \%$ of umbilical cord samples and $69.4 \%$ of plasma samples at age 11. Mean $p, p$ '-DDT concentrations at birth and age 11 were 24.45 , and $6.93 \mu \mathrm{gg} / \mathrm{kg}$ 
plasma lipids, respectively. Mean $p, p^{\prime}$-DDE concentration at birth was 509.27, whereas $p, p$ '-DDE concentrations at age 11 were approximately half of these values at $268.54 \mu \mathrm{g} / \mathrm{kg}$ plasma lipids .

\subsection{Associations of $p, p^{\prime}$-DDT and p,p'-DDE exposure with VEP}

Multivariate linear regression analyses were conducted to examine the association between contaminants and VEPs by taking account of the control variables according to a change-inestimate approach (see method section for details). Only final regression models with a p-value $<$ 0.2 are shown in Table 3. After adjusting for confounders, umbilical cord $p, p$ '-DDE plasma concentration was significantly associated with increased N150 amplitude at the lowest contrast (4\%) (see Figure 1A). The $\beta$ coefficients indicate that an increase of $p, p$ '-DDE concentration of one logarithm unit is associated with an increase in amplitude of $0.72 \mu \mathrm{V}$ (i.e., 0.28 SD). Prenatal $p, p$ 'DDE exposure was also associated with increased N150 at the 95\% contrast level, but that effect fell short of statistical significance. No association was detected with current $p, p^{\prime}$-DDT or $p, p$ 'DDE plasma concentrations.

Considering the important visual system reorganisation occurring during the first years of life, and knowing the greater vulnerability to neurotoxic insult during development, we asked whether DDT and DDE exposure during this period could also alter 11-year VEPs. Thus, because these contaminants were also measured at age 5 years in a subsample of the children $(n=56)$ taking part in the present VEP follow-up study, we conducted further analyses to assess the association between $p, p$ '-DDT and $p, p^{\prime}$-DDE concentrations at preschool aged and VEP measured at age 11. Of note, the VEP responses of these 56 children, either in terms of amplitude or latency, were comparable to those of the other children in the sample $(\mathrm{p}>0.05)$. Multiple regressions revealed that N75 amplitude at mid-contrast (30\%) was significantly decreased with increasing $p, p$ '-DDE plasma concentration at age 5 (see Figure 1B). The $\beta$ coefficients indicate that an increase of $p, p$ 'DDE concentration of one logarithm unit is associated with a decrease in amplitude on the order of 
$1.44 \mu \mathrm{V}$. Interestingly, $p, p^{\prime}$-DDE concentration at age 5 was very well predicted by cord $p, p$ '-DDE concentrations and breastfeeding duration. Cord $p, p^{\prime}$-DDE (standardized $\beta=0.43 p<0.0001$ ) and breastfeeding duration (standardized $\beta=0.59, \mathrm{p}<0.000001$ ) accounted for $54 \%$ of the total variance in plasma $p, p^{\prime}$-DDE at age 5, whereas 5-year $p, p^{\prime}$-DDT concentration was very well predicted by cord $p, p^{\prime}$-DDT concentrations (standardized $\beta=0.52, \mathrm{p}<0.000001$ ), but not at all by breastfeeding duration (standardized $\beta=0.14, \mathrm{~ns}$ ).

\section{Discussion}

The aim of this study was to assess the potential neurotoxic impact of prenatal and childhood exposure to organochlorine pesticides on visual processing in children. After controlling for the influence of socioeconomic factors, other environmental contaminants and nutrients, such as DHA, we found subtle and subclinical $p, p$ '-DDE relation to visual processing. Indeed significant associations were found between $p, p^{\prime}$-DDE prenatal and early childhood exposure and VEP responses at age 11 years. Prenatal p,p'-DDE exposure was significantly associated with increased N150 amplitude at the lowest visual contrast, whereas $p, p$ '-DDE exposure measured at age 5 years, which mainly reflects cumulative prenatal and infancy exposures, was significantly related to decreased N75 amplitude. One limitation of our study is the multiple comparisons involved in the analysis that was not corrected considering that correction methods are often too conservative for epidemiological studies (which may result in Type 2 error). As a consequence, we cannot exclude the possibility that some of our significant results are due to chance (Type 1 error).

Functional (Bradley and Freeman, 1982, Ellemberg et al., 1999) and anatomical (de Courten and Garey, 1983, Huttenlocher et al., 1982) data indicate that visual processes develop from the embryologic period and only reach an adult-like state at approximately 8 to 9 years of age. Our results therefore concur with the body of evidence indicating greater brain vulnerability to toxic insult during prenatal and early childhood periods (Grandjean and Landrigan, 2006, Rice and 
Barone, 2000). Indeed, toxic interference with sequence events underlying brain development can result in brain alterations even if the chemicals have no effect on a mature brain (Grandjean and Landrigan, 2006, Rice and Barone, 2000). Because vision develops during the perinatal and early childhood period, these periods appears to be a critical time for $p, p^{\prime}$-DDT and $p, p^{\prime}$-DDE exposure.

$p, p$ '-DDT and $p, p$ '-DDE are recognized endocrine disruptors, and are reported to alter estrogen, androgen, and thyroid functions (Danzo, 1997, Facemire et al., 1995, Fry and Toone, 1981, Gray et al., 2001, Guillette et al., 1994, Kelce et al., 1995, Moccia et al., 1986, T, 1992). Given the importance of steroid and thyroid hormones for orchestrating the complex temporal and regional processes of brain development, including cell proliferation, migration, differentiation, synaptogenesis, and myelinization (Beyer, 1999, Howdeshell, 2002, Porterfield and Hendrich, 1993, Thompson and Potter, 2000), the $p, p$ '-DDT and $p, p^{\prime}$-DDE association with visual function may result, at least in part, from interference with endocrine functions (Colborn, 2004, Howdeshell, 2002, Weiss, 2011). A more direct mechanism of action of $p, p$ '-DDE exposure on brain development may relate to its capacity to induce sustained hyperexcitability. Thus, $p, p$ '-DDT keeps voltage gated sodium channels open, thereby prolonging neuron depolarization, leading to central nervous system hyperexcitability (Davies et al., 2007, Narahashi and Haas, 1967). This may also occur by interfering with $\mathrm{K}+$ and $\mathrm{Ca}+$ transport across neural membranes via ATPase inhibition (Matsumura and Narahashi, 1971, Matsumura and Patil, 1969). These hyperexcitability states lead to different neurotoxic processes, including apoptotic cell death.

To our knowledge, only one study has assessed VEP responses associated with $p, p$ '-DDE exposure in early childhood (Riva et al., 2004). In that study, $p, p^{\prime}$-DDE and $p, p^{\prime}$-DDT concentrations in maternal milk were significantly correlated with increased P100 latency at age 12 months. However, after controlling for DHA concentrations measured in children's blood samples, mother's age, and area of residence, the partial correlation coefficient was no longer significant. Our contrasting results may be explained by different protocols and outcomes of interest. Riva et al. 
only assessed the P100 evoked at maximum contrast (100\%), with no measure of amplitude (only latency was considered). Because most of the significant associations between $p, p$ '-DDE exposure and VEP in the present study were revealed at mid- and low-contrast, our results underscore the need to use a VEP protocol with different contrasts to assess subtle differences in the developmental neurotoxicity of pollutants.

In the current study, $p, p$ '-DDE was associated with both increased and decreased VEP amplitude. In fact, the scalp-recorded VEP signal results from a summation of the excitatory and inhibitory postsynaptic potentials, and is generated by the synchronized activation of thousands of neurons. More specifically, VEP amplitude reflects both the numbers of neurons activated and the synchronization of their activity in response to visual stimulation (Luck, 2005). Our results therefore suggest that $p, p$ '-DDE alters the complex neuronal network organization and/or function in the visual cortex. There is consensus that the early component N75 represents mainly primary visual cortex (V1) activity and is related to the information conduction time from retina to V1 (Di Russo et al., 2002, Di Russo et al., 2005, Saint-Amour et al., 2005), and that the P100 and N150 components are dependent on both striate and extrastriate area activation (Di Russo et al., 2002, Di Russo et al., 2005, Saint-Amour et al., 2005). Consequently, the association of prenatal $p$, ' $^{-D D E}$ exposure with N150 alteration suggests that the $p, p$ '-DDE impact extends to extrastriate structures. Because the visual cortex undergoes important restructuration between the embryologic period and the first few years of life, mainly due to synaptic remodeling and elimination in response to the visual environment (Huttenlocher et al., 1982), our findings support the concept of greater vulnerability to toxicant exposure during critical periods of brain plasticity.

Due to the high intercorrelation between $p, p^{\prime}$-DDE or $p, p$ '-DDT and other organochlorine compounds the respective association with each of these compounds is statistically difficult to dissociate. Indeed, VEP alteration associated with $p, p$ '-DDE prenatal exposure could not be specific to this chemical but also attributable to other organochlorine compounds. In addition, because of the 
long half-life of these contaminants (i.e., many years), VEP alterations associated with $p, p$ '-DDE plasma concentrations at age 5 years could be attributable to bioaccumulative exposure to organochlorine compounds from infancy through breastfeeding and the traditional marine diet. It is noteworthy that cord PCB 153 concentrations were not significantly correlated with N150 amplitude ( $r=-0.08$, data not shown), suggesting that the association between the N150 response and cord plasma $p, p$ '-DDE is not mediated by PCB exposure. This result concurs with Ethier et al. (2012), who, using the same dataset as the present study, found no significant association between prenatal (or postnatal) exposure to PCB 153 and VEP responses at age 11 years.

Although $p, p^{\prime}$-DDT was banned in many countries a few decades ago, the $p, p^{\prime}$-DDT molecule in the present study in Nunavik was clearly detected in $80 \%$ and $70 \%$ of cord and childhood plasma samples, respectively. Moreover, its breakdown product $p, p$ '-DDE was detected and quantified in $100 \%$ of plasma samples. Our findings suggest that the $p, p$ '-DDE, not $p, p$ '-DDT, exposure concentrations present in Nunavik are capable of altering visual processing development. Regarding $p, p$ '-DDT, it is important to note that the data distribution may have been biased by the fact that about $30 \%$ of the data was under the detection limit level. In this case, a value equal to half the limit of detection of the analytical method was used, which affected the variance, the mean and the distribution of the data. Although the skewed-distribution criterion was respected, this procedure may have affected our results and may explain why no association was found with $p, p$ '-DDT. Another factor that may have affected our results is the a priori exclusion of participants who were premature or of low birth weight. Indeed, there is a possibility that these neurodevelopmental disorders were in the causal pathway between exposure and VEPs, which may have led to an underestimation of the associations. Our design did not allow testing this hypothesis because no follow-up study was conducted on these excluded participants.

Recent biomonitoring reports allow comparing Nunavik concentrations with those in the general population. Data from the Report on Human Biomonitoring of Environmental Chemicals in 
Canada, obtained between 2007 and 2009, indicate that the p,p'-DDE geometric mean of the Canadian population aged 20-39 years was $94.68 \mu \mathrm{g} / \mathrm{kg}$ plasma lipids (HealthCanada, 2010). Similar exposures were measured from 2003 to 2004 in the U.S. population (CDC, 2009) including age group from 12 to 19 years old, which is more comparable to the present 11-year blood sample. The $p$, $p^{\prime}$-DDE geometric mean in this U.S. population was $105 \mu \mathrm{g} / \mathrm{kg}$ plasma lipids, or $43 \%$ lower than that found in 11-year-olds in Nunavik (185.25 $\mu \mathrm{g} / \mathrm{kg}$ plasma lipids). Although cord and 5-yearold blood concentrations are not available in the U.S. or Canadian general populations, it is noteworthy that the $p, p$ '-DDE concentration measured at age 11 years in our study corresponds closely to the 75 th percentile of the U.S. $12-19$-year-old population $(167 \mu \mathrm{g} / \mathrm{kg}$ plasma lipids; $95 \%$ confidence interval $=123-240 \mu \mathrm{g} / \mathrm{kg}$ plasma lipids). These data suggested that around $25 \%$ of the general population may be exposed to $p, p^{\prime}$-DDE concentrations in the range of those found in Nunavik. Of note, $p, p^{\prime}$-DDE cord concentration in Nunavik are similar or even lower than cord concentrations found in other countries (Adetona et al., 2013, Patayova et al., 2013, Qu et al., 2010, Tan et al., 2009, Valvi et al., 2012). In other words, many populations may be exposed to $p$, $p$ '-DDE concentrations sufficient to potentially impair the development of visual processing.

The current study shows that $p, p^{\prime}$-DDE exposure both pre- and postnatally during the first years of life may impair visual processing in pre-adolescent children. To our knowledge, this is the first study to demonstrate subclinical alterations in visual system function in children exposed to pesticides throughout their childhood development. Although this deficit is subclinical, it may reflect neuronal insults and subtle brain organisation damage resulting from $p, p^{\prime}-\mathrm{DDT} / p, p^{\prime}$-DDE neurotoxicity. Clinical manifestations of such neurotoxocity may be temporarily masked by compensatory processes and become more apparent with natural age-related decline of functions (Rice, 1998). Moreover, this subclinical toxicity may lead to more children with clinical deficits when a larger part of the population is considered (Rice, 1998). In other words, our finding may have more meaning when interpreted at a population level. Therefore, in order to have a more 
accurate global picture of the integrity of brain function in children with relation to environmental contaminants, it is important, when assessing OCP developmental neurotoxicity, to consider sensory function in addition to cognitive functions.

\section{Acknowledgements}

We are grateful to the Inuit population in Nunavik for participating in this study. We also thank the medical and health care professionals at the village health centers and nursing stations for their invaluable assistance. We gratefully acknowledge the long-time support of the municipal councils of Puvirnituq, Inukjuaq, and Kuujuaq, the Centre de Toxicologie du Québec, the Public Health Department of Nunavik, and the Nunavik Nutrition and Health Committee. We thank Renee Sun, Line Roy, Johanne Varin, Brenda Tuttle, Jocelyne Gagnon and Neil Dodge for their involvement in data collection and data management.

This research was supported by the National Institute of Environmental Health and Sciences / U.S. National Institutes of Health (R01 ES07902 to J.L.J.), Indian and Northern Affairs Canada Northern Contaminants Program (G.M.), a Joseph Young, Sr., grant from the State of Michigan (S.W.J.), the Canadian Institutes of Health Research (D. S-A.), and the Nunavik Regional Board of Health and Social Services.

\section{Conflict of Interest statement}

The authors declare that there are no conflicts of interest. 


\section{Figure legend}

Figure 1. Scatterplots relating cord (A) and 5-year (B) p,p'-DDE exposures ( $\mu \mathrm{g} / \mathrm{kg}$ plasma lipids) to the VEP. After adjustment, cord p,p'-DDE exposure is associated with N150 amplitude increase at $4 \%$ of visual contrast whereas 5-year p,p'-DDE exposure is associated with N75 amplitude decrease at $30 \%$ of visual contrast. Natural log-transformed values were used for p,p'-DDE exposures. 


\section{References}

Abb M, Breuer JV, Zeitz C, Lorenz W. Analysis of pesticides and PCBs in waste wood and house dust. Chemosphere. 2010;81:488-93.

Adetona O, Horton K, Sjodin A, Jones R, Hall DB, Aguillar-Villalobos M, et al. Concentrations of select persistent organic pollutants across pregnancy trimesters in maternal and in cord serum in Trujillo, Peru. Chemosphere. 2013.

Ayotte P, Muckle G, Jacobson JL, Jacobson SW, Dewailly E, Inuit Cohort S. Assessment of preand postnatal exposure to polychlorinated biphenyls: lessons from the Inuit Cohort Study. Environ Health Perspect. 2003;111:1253-8.

Barrie LA, Gregor D, Hargrave B, Lake R, Muir D, Shearer R, et al. Arctic contaminants: sources, occurrence and pathways. Sci Total Environ. 1992;122:1-74.

Beyer C. Estrogen and the developing mammalian brain. Anatomy and embryology. 1999;199:37990.

Boucher O, Bastien CH, Muckle G, Saint-Amour D, Jacobson SW, Jacobson JL. Behavioural correlates of the $\mathrm{P} 3 \mathrm{~b}$ event-related potential in school-age children. International journal of psychophysiology : official journal of the International Organization of Psychophysiology. 2010a; 76:148-57.

Boucher O, Bastien CH, Saint-Amour D, Dewailly E, Ayotte P, Jacobson JL, et al. Prenatal exposure to methylmercury and PCBs affects distinct stages of information processing: An eventrelated potential study with Inuit children. Neurotoxicology. 2010b;18:18.

Boucher O, Burden MJ, Muckle G, Saint-Amour D, Ayotte P, Dewailly E, et al. Response inhibition and error monitoring during a visual go/no-go task in inuit children exposed to lead, polychlorinated biphenyls, and methylmercury. Environ Health Perspect. 2012;120:608-15.

Boucher O, Muckle G, Saint-Amour D, Dewailly E, Ayotte P, Jacobson SW, et al. The relation of lead neurotoxicity to the event-related potential P3b component in Inuit children from arctic Quebec. Neurotoxicology. 2009;30:1070-7.

Bradley A, Freeman RD. Contrast sensitivity in children. Vision research. 1982;22:953-9.

Carter RC, Jacobson SW, Molteno CD, Chiodo LM, Viljoen D, Jacobson JL. Effects of prenatal alcohol exposure on infant visual acuity. J Pediatr. 2005;147:473-9.

Cartier C, Saint-Amour D. Prenatal Omega-3 Fatty Acids Intake and Visual Function. In: Preedy V, editor. Nutrition, Diet, the Eye and Vision: Elsevier; in press.

CDC. Fourth National Report on Human Exposure to Environmental Chemicals Atlanta, GA: U.S. Department of Health and Human Services, Center for Disease Control and Prevention; 2009.

Cohn BA, Wolff MS, Cirillo PM, Sholtz RI. DDT and breast cancer in young women: new data on the significance of age at exposure. Environ Health Perspect. 2007;115:1406-14.

Colborn T. Neurodevelopment and endocrine disruption. Environ Health Perspect. 2004;112:944-9.

Danzo BJ. Environmental xenobiotics may disrupt normal endocrine function by interfering with the binding of physiological ligands to steroid receptors and binding proteins. Environ Health Perspect. 1997; 105:294-301.

Davies TG, Field LM, Usherwood PN, Williamson MS. DDT, pyrethrins, pyrethroids and insect sodium channels. IUBMB life. 2007;59:151-62.

de Courten C, Garey LJ. [Morphological development of the primary visual pathway in the child]. Journal francais d'ophtalmologie. 1983;6:187-202.

De Jager C, Farias P, Barraza-Villarreal A, Avila MH, Ayotte P, Dewailly E, et al. Reduced seminal parameters associated with environmental DDT exposure and p,p'-DDE concentrations in men in Chiapas, Mexico: a cross-sectional study. J Androl. 2006;27:16-27.

Dewailly E, Ayotte P, Bruneau S, Gingras S, Belles-Isles M, Roy R. Susceptibility to infections and immune status in Inuit infants exposed to organochlorines. Environ Health Perspect. 2000;108:20511. 
Dewailly E, Ayotte P, Bruneau S, Laliberte C, Muir DC, Norstrom RJ. Inuit exposure to organochlorines through the aquatic food chain in arctic quebec. Environ Health Perspect. 1993;101:618-20.

Di Russo F, Martinez A, Sereno MI, Pitzalis S, Hillyard SA. Cortical sources of the early components of the visual evoked potential. Human brain mapping. 2002;15:95-111.

Di Russo F, Pitzalis S, Spitoni G, Aprile T, Patria F, Spinelli D, et al. Identification of the neural sources of the pattern-reversal VEP. NeuroImage. 2005;24:874-86.

Diaz G, Ortiz R, Schettino B, Vega S, Gutierrez R. Organochlorine pesticides residues in bottled drinking water from Mexico City. Bulletin of environmental contamination and toxicology. 2009;82:701-4.

Ellemberg D, Lewis TL, Liu CH, Maurer D. Development of spatial and temporal vision during childhood. Vision research. 1999;39:2325-33.

Eskenazi B, Marks AR, Bradman A, Fenster L, Johnson C, Barr DB, et al. In utero exposure to dichlorodiphenyltrichloroethane (DDT) and dichlorodiphenyldichloroethylene (DDE) and neurodevelopment among young Mexican American children. Pediatrics. 2006;118:233-41.

Ethier AA, Muckle G, Bastien C, Dewailly E, Ayotte P, Arfken C, et al. Effects of environmental contaminant exposure on visual brain development: a prospective electrophysiological study in school-aged children. Neurotoxicology. 2012;33:1075-85.

Facemire CF, Gross TS, Guillette LJ, Jr. Reproductive impairment in the Florida panther: nature or nurture? Environ Health Perspect. 1995;103 Suppl 4:79-86.

Fry DM, Toone CK. DDT-induced feminization of gull embryos. Science. 1981;213:922-4.

Grandjean P, Landrigan PJ. Developmental neurotoxicity of industrial chemicals. Lancet. 2006;368:2167-78.

Gray LE, Ostby J, Furr J, Wolf CJ, Lambright C, Parks L, et al. Effects of environmental antiandrogens on reproductive development in experimental animals. Human reproduction update. 2001;7:248-64.

Guillette LJ, Jr., Gross TS, Masson GR, Matter JM, Percival HF, Woodward AR. Developmental abnormalities of the gonad and abnormal sex hormone concentrations in juvenile alligators from contaminated and control lakes in Florida. Environ Health Perspect. 1994;102:680-8.

HealthCanada. Report on Human Biomonitoring of Environmental Chemicals in Canada. Health Canada; 2010.

Hermanowicz A, Nawarska Z, Borys D, Maslankiewicz A. The neutrophil function and infectious diseases in workers occupationally exposed to organochloride insecticides. Int Arch Occup Environ Health. 1982;50:329-40.

Howdeshell KL. A model of the development of the brain as a construct of the thyroid system. Environ Health Perspect. 2002;110 Suppl 3:337-48.

Huttenlocher PR, de Courten C, Garey LJ, Van der Loos H. Synaptogenesis in human visual cortex-evidence for synapse elimination during normal development. Neuroscience letters. 1982;33:24752.

Jacobson JL, Jacobson SW. Intellectual impairment in children exposed to polychlorinated biphenyls in utero. N Engl J Med. 1996;335:783-9.

Jacobson JL, Jacobson SW, Muckle G, Kaplan-Estrin M, Ayotte P, Dewailly E. Beneficial effects of a polyunsaturated fatty acid on infant development: evidence from the inuit of arctic Quebec. J Pediatr. 2008;152:356-64.

Jacques C, Levy E, Muckle G, Jacobson SW, Bastien C, Dewailly E, et al. Long-term effects of prenatal omega-3 fatty acid intake on visual function in school-age children. J Pediatr. 2011;158:8390, e1.

Kaushik CP, Sharma HR, Kaushik A. Organochlorine pesticide residues in drinking water in the rural areas of Haryana, India. Environmental monitoring and assessment. 2012;184:103-12. 
Kelce WR, Stone CR, Laws SC, Gray LE, Kemppainen JA, Wilson EM. Persistent DDT metabolite p,p'-DDE is a potent androgen receptor antagonist. Nature. 1995;375:581-5.

Korrick SA, Sagiv SK. Polychlorinated biphenyls, organochlorine pesticides and neurodevelopment. Curr Opin Pediatr. 2008;20:198-204.

Luck SJ. An introduction to the event-related potential technique: The Massachussets Institute of Technology Press; 2005.

Maldonado G, Greenland S. Simulation study of confounder-selection strategies. Am J Epidemiol. 1993;138:923-36.

Matsumura F, Narahashi T. ATPase inhibition and electrophysiological change caused by DDT and related neuroactive agents in lobster nerve. Biochemical pharmacology. 1971;20:825-37.

Matsumura F, Patil KC. Adenosine triphosphatase. Sensitive to DDT in synapses of rat brain. Science. 1969;166:121-2.

McGlynn KA, Quraishi SM, Graubard BI, Weber JP, Rubertone MV, Erickson RL. Persistent organochlorine pesticides and risk of testicular germ cell tumors. Journal of the National Cancer Institute. 2008;100:663-71.

Moccia RD, Fox GA, Britton A. A quantitative assessment of thyroid histopathology of herring gulls (Larus argentatus) from the Great Lakes and a hypothesis on the causal role of environmental contaminants. Journal of wildlife diseases. 1986;22:60-70.

Molloy C, Doyle LW, Makrides M, Anderson PJ. Docosahexaenoic Acid and Visual Functioning in Preterm Infants: A Review. Neuropsychology review. 2012.

Montgomery MP, Kamel F, Saldana TM, Alavanja MC, Sandler DP. Incident diabetes and pesticide exposure among licensed pesticide applicators: Agricultural Health Study, 1993-2003. Am J Epidemiol. 2008;167:1235-46.

Morse NL. Benefits of Docosahexaenoic Acid, Folic Acid, Vitamin D and Iodine on Foetal and Infant Brain Development and Function Following Maternal Supplementation during Pregnancy and Lactation. Nutrients. 2012;4:799-840.

Muckle G, Ayotte P, Dewailly EE, Jacobson SW, Jacobson JL. Prenatal exposure of the northern Quebec Inuit infants to environmental contaminants. Environ Health Perspect. 2001;109:1291-9.

Muckle G, Dewailly E, Ayotte P. Prenatal exposure of Canadian children to polychlorinated biphenyls and mercury. Canadian journal of public health Revue canadienne de sante publique. 1998;89 Suppl 1:S20-5, 2-7.

Multigner L, Ndong JR, Giusti A, Romana M, Delacroix-Maillard H, Cordier S, et al. Chlordecone exposure and risk of prostate cancer. J Clin Oncol. 2010;28:3457-62.

Murata K, Weihe P, Renzoni A, Debes F, Vasconcelos R, Zino F, et al. Delayed evoked potentials in children exposed to methylmercury from seafood. Neurotoxicology and teratology. 1999;21:3438.

Narahashi T, Haas HG. DDT: interaction with nerve membrane conductance changes. Science. 1967; 157:1438-40.

Odom JV, Bach M, Barber C, Brigell M, Marmor MF, Tormene AP, et al. Visual evoked potentials standard (2004). Documenta ophthalmologica Advances in ophthalmology. 2004;108:115-23.

Otto DA. The assessment of neurotoxicity in children. Electrophysiological methods. Monogr Am Assoc Ment Defic. 1987:139-58.

Patayova H, Wimmerova S, Lancz K, Palkovicova L, Drobna B, Fabisikova A, et al. Anthropometric, socioeconomic, and maternal health determinants of placental transfer of organochlorine compounds. Environmental science and pollution research international. 2013.

Patel CJ, Bhattacharya J, Butte AJ. An Environment-Wide Association Study (EWAS) on type 2 diabetes mellitus. PLoS One. 2010;5:e10746.

Plusquellec P, Muckle G, Dewailly E, Ayotte P, Begin G, Desrosiers C, et al. The relation of environmental contaminants exposure to behavioral indicators in Inuit preschoolers in Arctic Quebec. Neurotoxicology. 2010;31:17-25. 
Porterfield SP, Hendrich CE. The role of thyroid hormones in prenatal and neonatal neurological development--current perspectives. Endocrine reviews. 1993;14:94-106.

Puertas R, Lopez-Espinosa MJ, Cruz F, Ramos R, Freire C, Perez-Garcia M, et al. Prenatal exposure to mirex impairs neurodevelopment at age of 4 years. Neurotoxicology. 2010;31:154-60.

Qu W, Suri RP, Bi X, Sheng G, Fu J. Exposure of young mothers and newborns to organochlorine pesticides (OCPs) in Guangzhou, China. Sci Total Environ. 2010;408:3133-8.

Rhainds M, Levallois P, Dewailly E, Ayotte P. Lead, mercury, and organochlorine compound levels in cord blood in Quebec, Canada. Archives of environmental health. 1999;54:40-7.

Ribas-Fito N, Cardo E, Sala M, Eulalia de Muga M, Mazon C, Verdu A, et al. Breastfeeding, exposure to organochlorine compounds, and neurodevelopment in infants. Pediatrics. 2003;111:e580-5.

Ribas-Fito N, Torrent M, Carrizo D, Julvez J, Grimalt JO, Sunyer J. Exposure to hexachlorobenzene during pregnancy and children's social behavior at 4 years of age. Environ Health Perspect. 2007;115:447-50.

Ribas-Fito N, Torrent M, Carrizo D, Munoz-Ortiz L, Julvez J, Grimalt JO, et al. In utero exposure to background concentrations of DDT and cognitive functioning among preschoolers. Am J Epidemiol. 2006;164:955-62.

Rice D, Barone S, Jr. Critical periods of vulnerability for the developing nervous system: evidence from humans and animal models. Environ Health Perspect. 2000;108 Suppl 3:511-33.

Rice DC. Issues in developmental neurotoxicology: interpretation and implications of the data. Canadian journal of public health Revue canadienne de sante publique. 1998;89 Suppl 1:S31-6, S440.

Riva E, Grandi F, Massetto N, Radaelli G, Giovannini M, Zetterstrom R, et al. Polychlorinated biphenyls in colostral milk and visual function at 12 months of life. Acta paediatrica. 2004;93:11037.

Rogan WJ, Gladen BC, McKinney JD, Carreras N, Hardy P, Thullen J, et al. Neonatal effects of transplacental exposure to PCBs and DDE. J Pediatr. 1986;109:335-41.

Romieu I, Hernandez-Avila M, Lazcano-Ponce E, Weber JP, Dewailly E. Breast cancer, lactation history, and serum organochlorines. Am J Epidemiol. 2000;152:363-70.

Sagiv SK, Thurston SW, Bellinger DC, Tolbert PE, Altshul LM, Korrick SA. Prenatal organochlorine exposure and behaviors associated with attention deficit hyperactivity disorder in school-aged children. Am J Epidemiol. 2010;171:593-601.

Saint-Amour D, Roy MS, Bastien C, Ayotte P, Dewailly E, Despres C, et al. Alterations of visual evoked potentials in preschool Inuit children exposed to methylmercury and polychlorinated biphenyls from a marine diet. Neurotoxicology. 2006;27:567-78.

Saint-Amour D, Saron CD, Schroeder CE, Foxe JJ. Can whole brain nerve conduction velocity be derived from surface-recorded visual evoked potentials? A re-examination of Reed, Vernon, and Johnson (2004). Neuropsychologia. 2005;43:1838-44.

Sala M, Ribas-Fito N, Cardo E, de Muga ME, Marco E, Mazon C, et al. Levels of hexachlorobenzene and other organochlorine compounds in cord blood: exposure across placenta. Chemosphere. 2001;43:895-901.

Scher MS, Richardson GA, Robles N, Geva D, Goldschmidt L, Dahl RE, et al. Effects of prenatal substance exposure: altered maturation of visual evoked potentials. Pediatric neurology. 1998;18:236-43.

Shen H, Main KM, Andersson AM, Damgaard IN, Virtanen HE, Skakkebaek NE, et al. Concentrations of persistent organochlorine compounds in human milk and placenta are higher in Denmark than in Finland. Hum Reprod. 2008;23:201-10.

Sjodin A, Wong LY, Jones RS, Park A, Zhang Y, Hodge C, et al. Serum concentrations of polybrominated diphenyl ethers (PBDEs) and polybrominated biphenyl (PBB) in the United States population: 2003-2004. Environ Sci Technol. 2008;42:1377-84. 
T C. Our stolen future. 1992.

Tan J, Loganath A, Chong YS, Obbard JP. Exposure to persistent organic pollutants in utero and related maternal characteristics on birth outcomes: a multivariate data analysis approach. Chemosphere. 2009;74:428-33.

Thompson CC, Potter GB. Thyroid hormone action in neural development. Cerebral cortex. 2000;10:939-45.

Torres-Sanchez L, Rothenberg SJ, Schnaas L, Cebrian ME, Osorio E, Del Carmen Hernandez M, et al. In utero p,p'-DDE exposure and infant neurodevelopment: a perinatal cohort in Mexico. Environ Health Perspect. 2007;115:435-9.

Valvi D, Mendez MA, Martinez D, Grimalt JO, Torrent M, Sunyer J, et al. Prenatal concentrations of polychlorinated biphenyls, DDE, and DDT and overweight in children: a prospective birth cohort study. Environ Health Perspect. 2012;120:451-7.

Wang RY, Jain RB, Wolkin AF, Rubin CH, Needham LL. Serum concentrations of selected persistent organic pollutants in a sample of pregnant females and changes in their concentrations during gestation. Environ Health Perspect. 2009;117:1244-9.

Weiss B. Endocrine disruptors as a threat to neurological function. Journal of the neurological sciences. 2011;305:11-21. 
A

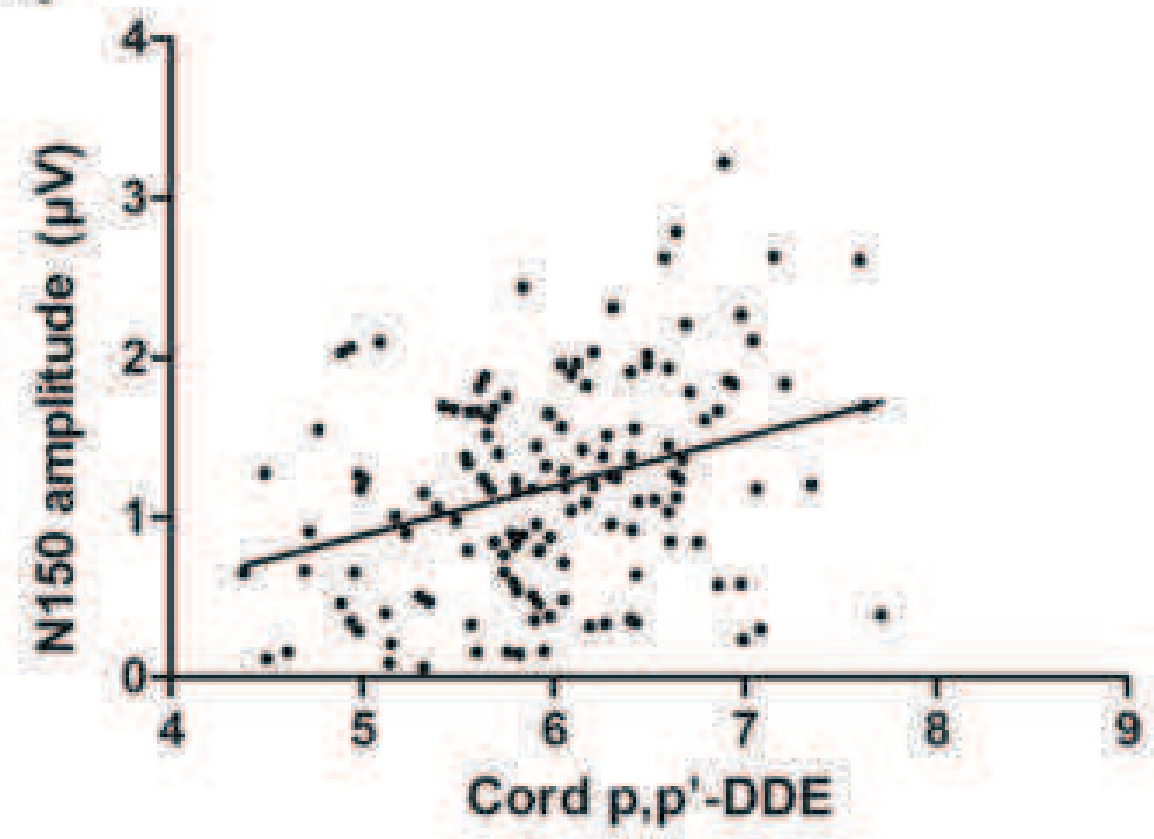

B

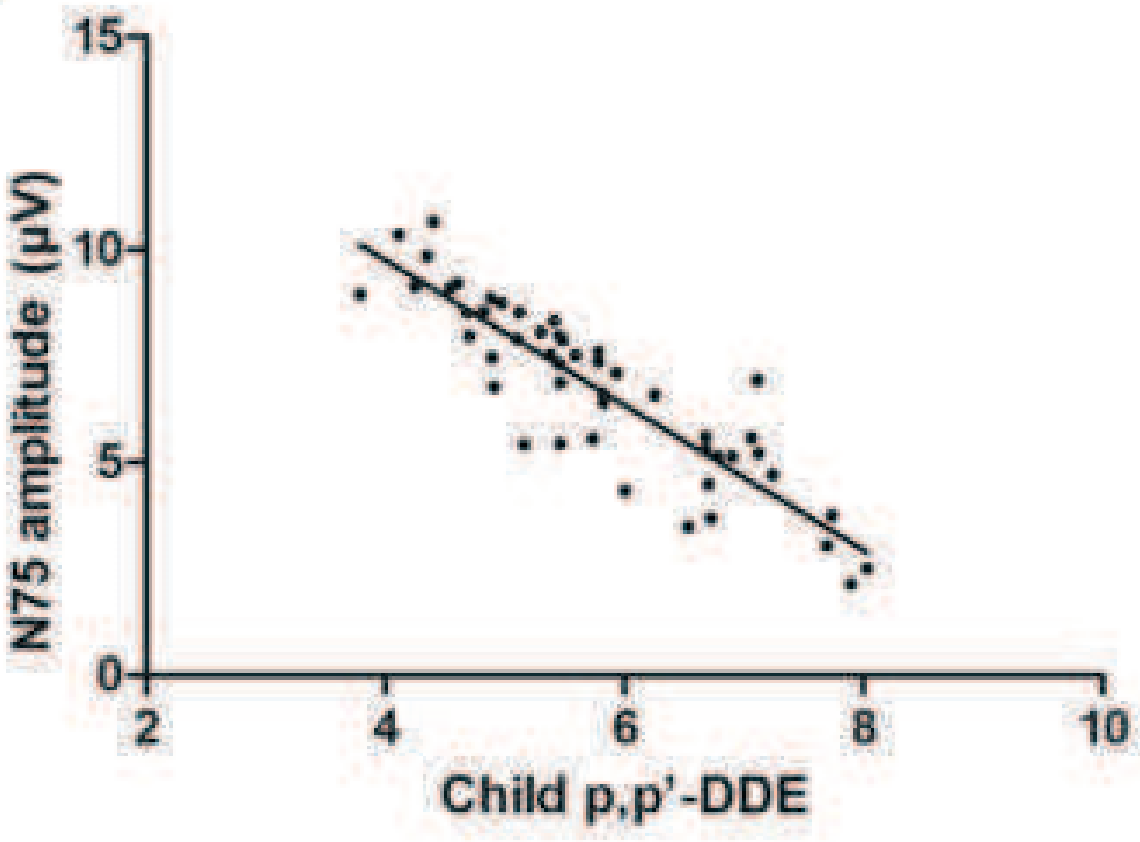


Table 1. Descriptive statistics for the participants

\begin{tabular}{|c|c|c|c|c|c|c|c|}
\hline & \multicolumn{3}{|c|}{ VEP participants } & \multicolumn{3}{|c|}{ Other participants } & \multirow{2}{*}{$\frac{\text { Difference }}{\mathrm{p} \text { value }^{1}}$} \\
\hline & $\mathrm{N}$ & Mean (SD) & Range & $\mathrm{N}$ & Mean (SD) & Range & \\
\hline \multicolumn{8}{|l|}{ Child's characteristics } \\
\hline Age at testing & 150 & $11.3(0.6)$ & $9.8-12.9$ & 144 & $11.2(0.9)$ & $8.5-14.3$ & 0.47 \\
\hline Sex (\%female) & 150 & 50.7 & & 144 & 49.3 & & 0.82 \\
\hline Hemoglobin concentration at testing time $(\mathrm{g} / \mathrm{L})$ & 147 & $130.6(8.8)$ & $105-149$ & 144 & $128.4(11.2)$ & $85-152$ & 0.06 \\
\hline Breastfeeding duration (months) & 146 & $10.5(17.3)$ & $0-108$ & 136 & $12.9(15.9)$ & $0-60$ & 0.22 \\
\hline \multicolumn{8}{|l|}{ Primary caregiver's characteristics } \\
\hline Parity & 150 & $2.1(1.8)$ & $0-8$ & 144 & $2(1.9)$ & $0-9$ & 0.83 \\
\hline Number of years of schooling & 149 & $8.3(2.7)$ & $0-16$ & 144 & $8.6(2.2)$ & $0-13$ & 0.35 \\
\hline Socio-economic status & 150 & $29.5(12.4)$ & $8-66$ & 144 & $27.2(10.7)$ & $8-54.5$ & 0.09 \\
\hline \multicolumn{8}{|l|}{ Prenatale exposure } \\
\hline Smoking during pregnancy (\% yes) & 143 & 81.1 & & 143 & 88.2 & & 0.07 \\
\hline Marijuana use during pregnancy ( $\%$ yes) & 117 & 23.9 & & 134 & 40.3 & & 0.01 \\
\hline Alcohol use during pregnancy (\% yes) & 118 & 49.2 & & 135 & 51.9 & & 0.67 \\
\hline p,p'-DDT ( $\mu \mathrm{g} / \mathrm{kg}$ plasma lipids) & 146 & $24.5(23.2)$ & $4.5-160.4$ & 136 & $21.2(23.2)$ & 4.2-191.4 & 0.24 \\
\hline p,p'-DDE ( $\mu \mathrm{g} / \mathrm{kg}$ plasma lipids) & 146 & $509.3(395.3)$ & $80.1-2239.1$ & 136 & $462.7(436)$ & $51.2-3421.5$ & 0.35 \\
\hline Selenium $(\mu \mathrm{mol} / \mathrm{L})$ & 135 & $4.7(2.5)$ & $1.9-20$ & 130 & $3.9(1.9)$ & $1.4-7.5$ & 0.01 \\
\hline DHA (\% phospholipids) & 144 & $3.7(1.3)$ & $1.1-7.7$ & 134 & $3.6(1.2)$ & $1.4-7.5$ & 0.92 \\
\hline
\end{tabular}

p,p'-DDT = 1,1,1-trichloro-2,2-bis(p-chlorophenyl)ethane; p,p'-DDT = 1,1,1-trichloro-2,2-bis(p-chlorophenyl)ethane.

DHA $=$ Docosahexaenoic acid.

${ }^{1}$ T-tests and chi-sqared were used for parametric and non-parametric comparisons, respectively 
Table 2. Intercorrelations among contaminants in cord and 11-year plasma samples.

\begin{tabular}{|c|c|c|c|c|c|c|c|c|c|c|}
\hline \multicolumn{2}{|c|}{$\underline{p, p^{\prime}-\mathrm{DDT}}$} & \multicolumn{2}{|c|}{$p, p^{\prime}-\mathrm{DDE}$} & \multicolumn{2}{|c|}{ Oxychlordane } & \multicolumn{2}{|c|}{ cis -nonachlor } & \multicolumn{3}{|c|}{ trans -nonachlor PCB 153} \\
\hline Cord & 11 years & Cord & 11 years & Cord & 11 years & Cord & 11 years & Cord 11 years & Cord & 11 years \\
\hline \multicolumn{11}{|l|}{$p, p^{\prime}-\mathrm{DDT}$} \\
\hline Cord & $0.49^{* * *}$ & $0.71^{* * *}$ & $0.48^{* * *}$ & $0.63^{* * *}$ & $0.51^{* * *}$ & $0.66^{* * *}$ & $0.51^{* * *}$ & $0.72^{* * *} 0.53^{* * *}$ & $0.57^{* * *}$ & * $0.41^{* * *}$ \\
\hline 11 years & & $0.42^{* * *}$ & $0.67^{* * *}$ & $0.46^{* * *}$ & $0.64^{* * *}$ & $0.40^{* * *}$ & $0.74^{* * *}$ & $0.50^{* * *} 0.73^{* * *}$ & $0.40^{* * *}$ & * $0.54^{* * *}$ \\
\hline \multicolumn{11}{|l|}{$p, p^{\prime}-\mathrm{DDE}$} \\
\hline Cord & & & $0.46^{* * *}$ & $0.84^{* * *}$ & $0.43^{* * *}$ & $0,77^{* * *}$ & $0.42^{* * *}$ & $0.87^{* * *} 0.44^{* * *}$ & $0.89^{* * *}$ & * $0.41^{* * *}$ \\
\hline 11 years & & & & $0.46^{* * *}$ & $0.93^{* * *}$ & $0.43^{* * *}$ & $0.90^{* * *}$ & $0.49^{* * *} 0.93^{* * *}$ & $0.44^{* * *}$ & *0.94** \\
\hline \multicolumn{11}{|l|}{ Oxychlordane } \\
\hline Cord & & & & & $0.55^{* * *}$ & $0.85^{* * *}$ & $0.51^{* * *}$ & $0.96^{* * *} 0.53^{* * *}$ & $0.88^{* * *}$ & * $0.47^{* * *}$ \\
\hline 11 years & & & & & & $0.48^{* * *}$ & $0.94^{* * *}$ & $0.56^{* * *} 0.98^{* * *}$ & $0.46^{* * *}$ & * $0.94^{* * *}$ \\
\hline \multicolumn{11}{|l|}{ cis-nonachlor } \\
\hline Cord & & & & & & & $0.49^{* * *}$ & $0.90^{* * *} 0.57^{* * *}$ & $0.81^{* * *}$ & * $0.42^{* * *}$ \\
\hline 11 years & & & & & & & & $0.55^{* * *} 0.98^{* * * *}$ & $0.42^{* * *}$ & * $0.84^{* * * *}$ \\
\hline \multicolumn{11}{|l|}{ trans -nonachlor } \\
\hline Cord & & & & & & & & & $0.88^{* * *}$ & * $0.47^{* * *}$ \\
\hline 11 years & & & & & & & & & & $0.90^{* * *}$ \\
\hline \multicolumn{11}{|l|}{ PCB 153} \\
\hline Cord & & & & & & & & & & $0.48^{* * *}$ \\
\hline
\end{tabular}

Log transformations were performed for p,p'DDT, p,p'-DDE, Oxychlordane, cis -nonachlor, trans -nonachlor and PCB concentrations.

$p, p^{\prime}$-DDT = 1,1,1-trichloro-2,2-bis(p-chlorophenyl)ethane;

$p, p^{\prime}$-DDE $=1,1$, -dichloro-2,2-bis(p-chlorophenyl)ethylene;

$\mathrm{PCB}=$ Polychlorinated biphenyl congener IUPAC 153.

${ }^{*} \mathrm{p}<0.05$.

${ }^{* * *} \mathrm{p}<0.01$.

${ }^{* * *} \mathrm{p}<0.001$. 
Table 3. Descriptive statistics for the biological samples

\begin{tabular}{|c|c|c|c|c|c|}
\hline \multirow{2}{*}{ Contaminants } & \multirow[t]{2}{*}{$\mathrm{N}$} & \multicolumn{2}{|c|}{ Geometric Mean Arithmetic Mean } & \multirow[t]{2}{*}{$\mathrm{SD}$} & \multirow[t]{2}{*}{ Range } \\
\hline & & & & & \\
\hline \multicolumn{6}{|l|}{ At birth (cord blood) } \\
\hline$p, p^{\prime}$-DDT ( $\mu \mathrm{g} / \mathrm{kg}$ plasma lipids) & 146 & 18.27 & 24.45 & 23.20 & $4.46-160.40$ \\
\hline$p, p^{\prime}-\mathrm{DDE}$ ( $\mu \mathrm{g} / \mathrm{kg}$ plasma lipids) & 146 & 399.26 & 509.27 & 395.31 & $80.10-2239.09$ \\
\hline PCB-153 ( $\mu \mathrm{g} / \mathrm{kg}$ plasma lipids) & 146 & 101.65 & 128.84 & 98.35 & $21.60-653.60$ \\
\hline $\mathrm{Pb}(\mu \mathrm{mol} / \mathrm{L})$ & 147 & 0.18 & 0.22 & 0.15 & $0.04-0.94$ \\
\hline $\mathrm{Hg}(\mathrm{nmol} / \mathrm{L})$ & 147 & 76.52 & 103.57 & 78.54 & $9-442$ \\
\hline \multicolumn{6}{|l|}{ At 11 years (blood sample) } \\
\hline$p, p^{\prime}$-DDT ( $\mu \mathrm{g} / \mathrm{kg}$ plasma lipids) & 144 & 5.28 & 6.93 & 5.68 & $1.52-43.55$ \\
\hline$p, p^{\prime}$-DDE ( $\mu \mathrm{g} / \mathrm{kg}$ plasma lipids) & 146 & 185.25 & 268.54 & 265.14 & $30.43-1803.92$ \\
\hline PCB-153 ( $\mu \mathrm{g} / \mathrm{kg}$ plasma lipids) & 146 & 50.43 & 79.8 & 95.23 & $4.13-809.52$ \\
\hline $\mathrm{Pb}(\mu \mathrm{mol} / \mathrm{L})$ & 147 & 0.10 & 0.12 & 0.11 & $0.02-0.62$ \\
\hline $\mathrm{Hg}(\mathrm{nmol} / \mathrm{L})$ & 147 & 13.86 & 22.26 & 24.76 & $0.2-170$ \\
\hline \multicolumn{6}{|l|}{ Nutrients } \\
\hline \multicolumn{6}{|l|}{ At birth (cord blood) } \\
\hline Selenium $(\mu \mathrm{mol} / \mathrm{L})$ & 135 & 4.17 & 4.65 & 2.54 & $1.90-20$ \\
\hline DHA (\% phospholipids) & 144 & 3.42 & 3.65 & 1.26 & $1.12-7.73$ \\
\hline \multicolumn{6}{|l|}{ At 11 years (blood sample) } \\
\hline Selenium $(\mu \mathrm{mol} / \mathrm{L})$ & 147 & 2.33 & 2.52 & 1.26 & $0.86-12$ \\
\hline DHA (\% phospholipids) & 145 & 2.18 & 2.37 & 0.97 & $0.60-5.51$ \\
\hline
\end{tabular}

$p, p^{\prime}$-DDT $=1,1,1$-trichloro-2,2-bis(p-chlorophenyl)ethane;

$p, p^{\prime}$-DDE $=1,1$, -dichloro-2,2-bis(p-chlorophenyl)ethylene;

$\mathrm{PCB}=$ Polychlorinated biphenyl congener IUPAC $153 ; \mathrm{Pb}=$ Lead; Hg = Mercury;

DHA $=$ Docosahexaenoic acid. 
Table 4. Regression coefficients of $p, p^{\prime}$-DDT and $p, p^{\prime}$-DDE after adjustment for confounding variables.

\begin{tabular}{|c|c|c|c|c|c|c|}
\hline & VEP outcome & Contrast & $\mathrm{N}$ & Beta $^{\prime}$ & $\mathrm{p}$ value & $95 \% \mathrm{CI}$ \\
\hline Prenatal exposure & & & & & & \\
\hline Cord $p, p^{\prime}-\mathrm{DDE}^{\mathrm{a}, \mathrm{b}}$ & N150 amplitude & $95 \%$ & 134 & 1,06 & 0.086 & $-0.154 ; 2.269$ \\
\hline Cord $p, p p^{\prime}-\mathrm{DDE}^{\mathrm{a}, \mathrm{c}, \mathrm{d}, \mathrm{e}}$ & N150 amplitude & $4 \%$ & 140 & 0.721 & 0.036 & $0.048 ; 1.394$ \\
\hline \multicolumn{7}{|l|}{5 years exposure } \\
\hline$p, p^{\prime}-\mathrm{DDE}^{\mathrm{c}, \mathrm{f}}$ & N75 amplitude & $30 \%$ & 49 & -1.439 & 0.007 & $-2.461 ;-0.416$ \\
\hline$p, p^{\prime}-\mathrm{DDT}^{\mathrm{d}, \mathrm{g}, \mathrm{c}, \mathrm{h}, \mathrm{i}}$ & P100 latency & $12 \%$ & 52 & 1.513 & 0.188 & $-0.769 ; 3.794$ \\
\hline
\end{tabular}

$p, p$ '-DDE = 1,1,-dichloro-2,2-bis(p-chlorophenyl)ethylene;

$p, p^{\prime}$-DDT $=1,1,1$-trichloro-2,2-bis(p-chlorophenyl)ethane.

The order of the letters corresponds to the order of how the covariables were entered into the model, starting with the confounder showing the highest correlation with the outcome and proceeding to the confounder showing the next highest correlation: ${ }^{\mathrm{a}}$ parity, ${ }^{\mathrm{b}}$ smoking during pregnancy, ${ }^{\mathrm{c}} \mathrm{Pb} 11$ years, ${ }^{\mathrm{d}} \mathrm{Cord} \mathrm{Pb},{ }^{\mathrm{e}} \mathrm{Hg} 11$ years, ${ }^{\mathrm{f}} \mathrm{Cord}$ selenium,

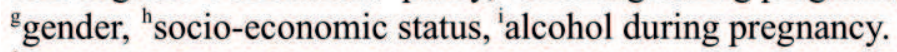

${ }^{1}$ Beta coefficients are unstandardized 